Stressful family environments and children's behavioral control:

A multimethod test and replication study with twins.

June 14th, 2017

CAmerican Psychological Association, [2108]. This paper is not the copy of record and may not exactly replicate the authoritative document published in the APA journal. Please do not copy or cite without author's permission. The final article is available, upon publication, at: [10.1037/fam0000345]"

Link to the publishers version: http://dx.doi.org/10.1037/fam0000345 
FAMILY STRESS AND CHILDREN'S BEHAVIORAL CONTROL

\begin{abstract}
Young children's behavioral control predicts a broad range of developmental outcomes in child- and adulthood. It is therefore important to study how individual differences in behavioral control arise. Previous studies suggest that there are both genetic and environmental influences, which were estimated in the current study using a sample of monoand dizygotic same-sex twins. Furthermore, we examined the associations between indicators of a stressful family environment like household chaos, parenting daily hassles, and parental depressive symptoms and children's behavioral control in two samples. Children of the same twin pair were randomly divided over two samples; a test $(N=201,48.3 \%$ boys, $M$ age 46.53 months) and replication sample ( $N=201,49.8 \%$ boys, $M$ age 46.06 months). Both parents reported on their children's effortful control via the Child Behavior Questionnaire and children's cheating behavior was observed during a throwing game. We found that AE models fitted the data for effortful control $(\mathrm{A}=31 \%, \mathrm{E}=69 \%)$ and cheating $(\mathrm{A}=16 \%, \mathrm{E}=$ 84\%) best. Path analyses revealed that children of parents experiencing more parenting daily hassles and depressive symptoms had lower levels of effortful control in both the test and replication sample. Furthermore, we found that children growing up in more chaotic households (parent report) had an increased risk of being in the cheating group versus the possible intention to cheat group in both samples. We suggest that the role of stressful family environments in the development of behavioral control should be considered when setting up prevention and intervention programs targeting children's behavioral control.
\end{abstract}

Key words:

behavioral control, household chaos, parenting daily hassles, parental depression, twins 
FAMILY STRESS AND CHILDREN'S BEHAVIORAL CONTROL

Stressful family environments and young children’s behavioral control:

A multimethod test and replication study with twins.

Young children's behavioral control predicts social, psychological and academic functioning in childhood (McClelland et al., 2007; Muris, van der Pennen, Sigmond, \& Mayer, 2008; Spinrad et al., 2007), as well as important adult outcomes like physical health, substance dependence, criminality and social economic status (SES) (Moffitt et al., 2011). Therefore, it is important to investigate why some children can control their behavior better than others. We explored the effects of environmental and genetic factors on children's behavioral control and investigated whether or not growing up in a stressful family environment is associated with children's ability to regulate their behavior. Results of previous studies indicated that children who grow up in a more stressful family environment show less behavioral control (Coplan, Bowker, \& Cooper, 2003; Evans, Gonnella, Marcynyszyn, Gentile, \& Salpekar, 2005; Hur, Buettner, \& Jeon, 2015; Sektnan, McClelland, Acock, \& Morrison, 2010). Although indicators of a stressful family environment like household chaos, parenting daily hassles and parental depressive symptoms are positively related to each other (Dumas et al., 2005; Hur et al., 2015; Rijlaarsdam et al., 2013; Shelleby et al., 2014), most studies focusing on the effects of a stressful family environment on children's behavioral control did not investigate all of these factors within the same model. Moreover, most studies relied on self-report data, which may reflect perceptions rather than actual behavior. We tried to overcome these limitations by testing a model including parent reports on parenting daily hassles, parental depressive symptoms and household chaos, and objective indicators of household chaos, i.e. noise during week and weekend days as well as crowding as predictors of children’s behavioral control. Behavioral control was measured with a questionnaire and an observation. 
FAMILY STRESS AND CHILDREN'S BEHAVIORAL CONTROL

\section{Behavioral control}

Behavioral control can be seen as an aspect of the broader concept of self-regulation and includes the ability to focus and maintain attention, follow instructions and inhibit inappropriate actions (McClelland et al., 2007). Another term that is often used to describe children's ability to regulate their behavior is effortful control, defined as "the efficiency of executive attention, including the ability to inhibit a dominant response and/or to activate a subdominant response, to plan, and to detect errors” (Rothbart \& Bates, 2006, p. 129). According to Kopp (1982), the ability to regulate behavior starts to emerge during toddlerhood. Toddlers begin to develop the ability to comply with requests from others and to plan their behavior. However, they often need help from their caregivers to control their behavior, especially under challenging circumstances (Bronson, 2000). In the next few years, the ability to control one’s own behavior generally develops quickly. Children gradually need less guidance and support from their caregivers during the preschool and kindergarten period and show more internal self-regulation (Kopp, 1982). However, large individual variations in children's levels of behavioral control have been found (McClelland et al., 2007). Previous studies suggest that variance in behavioral control is partly heritable. In a study focusing on effortful control in adults, an AE model was found to fit the data best, indicating both genetic and unique environmental effects (Yamagata et al., 2005). Gagne and Saudino (2016) tested ACE models for both observed and parent reported inhibitory control (IC) in two- and threeyear-olds and found an ACE model for parent reported IC, at age two, and an AE model at age three. For observed IC they found an AE model at age two and a CE model at age three. These results suggest only a small role for shared environmental factors (C) in explaining differences in children's behavioral control, although, as we will describe below, there are several studies showing significant relations between shared environmental factors and children's behavioral control. 
FAMILY STRESS AND CHILDREN'S BEHAVIORAL CONTROL

\section{Household chaos}

One of the environmental factors that has been suggested to affect the development of children in general, and more specifically behavioral control is household chaos. Chaotic households are characterized by high levels of noise and crowding (a large number of people gathered closely together), a lack of structure and routines and high-context traffic patterns (many people coming and going; Wachs, 1989). Household chaos has been related to a broad range of child outcomes, like school performance and internalizing and externalizing problem behavior (Hanscombe, Haworth, Davis, Jaffee, \& Plomin, 2011; Shamama-tus-Sabah, Gilani, Kamal, \& Batool, 2012). Although household chaos is related to SES in such a way that chaotic households are overrepresented in low SES families (Evans et al., 2005), household chaos seems to affect children’s development over and above SES (Wachs \& Evans, 2010).

Research focusing specifically on children's behavioral control showed that both preschoolers and children in elementary school had lower levels of behavioral control according to their parents and/or teachers when they grew up in chaotic households (Evans et al., 2005; Hardaway, Wilson, Shaw, \& Dishion, 2012; Valiente, Lemery-Chalfant, \& Reiser, 2007). The same relation with household chaos was found when the level of behavioral control in preschoolers was measured with observational tasks (Hur et al., 2015; Martin, Razza, \& Brooks-Gunn, 2012). The ability to regulate behavior thus seems to be inversely related to distracting, unstructured and unpredictable environments.

\section{Parenting daily hassles}

The term parenting daily hassles refers to minor parenting stresses that accompany childrearing and challenging child behavior (Crnic \& Greenberg, 1990). Parenting daily hassles have been suggested to affect children's development both directly and indirectly via parenting practices. A study including 141 families with typically developing preschoolers showed that mothers were less positive towards their child during parent-child interactions 
FAMILY STRESS AND CHILDREN'S BEHAVIORAL CONTROL

when they reported higher levels of parenting daily hassles. Furthermore, these mothers reported higher levels of behavior problems for their children (Crnic, Gaze, \& Hoffman, 2005). Rijlaarsdam et al. (2013) found that high levels of parenting stress when children were 1.5 years of age predicted children's externalizing problem behavior at 3 years of age as reported by their mother and Shelleby et al. (2014) found that the level of parenting daily hassles mothers experienced when their child was 3 to 4 years old was related to children's conduct problems when they were 7 to 8 years old (rating of mothers and teachers were combined). To our knowledge only a few studies examined the more specific relation between parental stress and children’s behavioral control (Barry, Dunlap, Cotten, Lochman, \& Wells, 2005; Coplan et al., 2003; Mathis \& Bierman, 2015), and they showed that the level of parenting daily hassles was negatively related to children’s ability to focus and maintain attention. However, all of these studies focused on children's attention problems, which is only part of the broader domain of behavioral control.

\section{Parental depressive symptoms}

Both maternal and paternal depressive symptoms have been found to be related to a range of negative outcomes, such as marital problems, low quality parenting behavior and several child problems (Cummings, Keller, \& Davies, 2005). Goodman and Gotlib (1999) proposed that children of depressed parents are exposed to a more stressful environment than children of non-depressed parents. The effect of parental depression on child development may therefore be mediated by the exposure to a variety of stressors associated with parental depression, like marital discord and financial stress. Another possible mechanism they proposed is through parenting practices. It was hypothesized that depressed mothers are more often unable to meet the social and emotional needs of their children, which in turn affects the child's development. 
FAMILY STRESS AND CHILDREN'S BEHAVIORAL CONTROL

With respect to children's behavioral control, it was found that mothers who experienced more depressive symptoms in the first 4.5 years of their children’s lives, reported lower levels of behavioral regulation of their child at 4.5 years of age (Sektnan et al., 2010). This negative relation was also found in a study by Gartstein and Fagot (2003); mothers who reported more depressive symptoms reported lower levels of effortful control in their children. This relation was not found for fathers. In another study however, it was found that a high level of paternal depressive symptoms in the postnatal period was associated with an increased risk of conduct problems and hyperactivity when the children were 42 months old (Ramchandani, Stein, Evans, O'Connor, \& Team, 2005).

\section{Current study}

In the current study of mono- and dizygotic same-sex twins, we investigated if environmental and genetic factors were related to children's behavioral control. We performed behavior-genetic analyses to estimate the relative contributions of genetics, shared and unique environments, and tested path models with variables indicating shared environment (parent reported household chaos, parenting daily hassles, depression, crowding) and unique environment (individual noise levels). The relations between these environmental factors and parent reported and observed behavioral control levels of children were tested across two sets of co-twins. If effects of the shared environmental factors tested in the path models would be found together with a $\mathrm{C}$ component in the classical twin models, the path analyses might reveal some of the specific shared environmental factors that explain the effect of the shared environment on children's behavioral control. If no C component would be found, alternative explanations, such as environmental mediation of genetic effects could be considered.

This study adds to the existing literature on behavioral control by testing a model that includes multiple indicators of a stressful family environment, measured not only with self- 
FAMILY STRESS AND CHILDREN'S BEHAVIORAL CONTROL

report measures but also with observational measures. Furthermore, we used the sample of twins to replicate the path models. Because the two sets of co-twins are similar in many respects the chance for replication is optimized, and lack of replication cannot easily be explained by varying confounders or other differences between samples.

\section{Hypotheses}

We expected that differences in children's behavioral control would be only partly explained by genetics. Furthermore, we expected that children who grow up in a more stressful family environment would show lower levels of both parent reported and observed behavioral control than children who grow up in a less stressful family environment.

\section{Method}

\section{Participants}

The sample includes families with a mono- or dizygotic same-sex twin participating in the longitudinal L-CID preschooler project, a study examining the efficacy of the VideoIntervention to promote Positive Parenting - Sensitive Discipline (VIPP-SD) in twin families (see Euser et al., 2016). The VIPP-SD is a short-term, behaviorally focused intervention program which aims to enhance parental sensitivity and the use of adequate discipline strategies. Ethical approval for this longitudinal study was granted by the Centrale Commissie Mensgebonden Onderzoek (CCMO; NL49069.000.14, Samen Uniek). Municipalities in the western region of the Netherlands provided contact information of families with same-sex twins who were between 31 and 51 months old at the time. The families received a letter with information about the study. Interested families were contacted via telephone to check inclusion criteria. Families were eligible if the parents were fluent in Dutch and if the children were physically and mentally able to perform all tasks. More information about the recruitment and complete sample of the L-CID preschooler project can be found elsewhere (Euser et al., 2016). A random split was performed to divide children of the same twin pair 


\section{FAMILY STRESS AND CHILDREN'S BEHAVIORAL CONTROL}

across two samples; a test and replication sample. For the current study, children with complete data on behavioral control as measured with the throwing game (see below) were selected $(N=418)$. The test sample included 201 children (48.3\% boys) and the replication sample 217 children (49.8\% boys). Differences in the group size stem from the selection of participants as described above. All children were between 34 and 66 months old when the data for the current study was collected, with a mean age of 46.53 months ( $S D=6.89)$ in the test sample and 46.06 months $(S D=6.94)$ in the replication sample. In most families, the twins and their biological parents were born in the Netherlands (test; 91.5\%, replication; 92.2\%), the majority of the children (test; 95\%, replication; 94.9\%) was raised by two parents, and in most cases, the primary parent, e.g. the person that spends most of the time with the children, was the biological mother (test; 93\%, replication; 92.2\%). All primary parents were between 22 to 53 years old, with a mean age of 36.58 years $(S D=4.55)$ in the test sample and 36.75 years $(S D=4.44)$ in the replication sample. The other parent was on average 38.24 years old $(S D=5.44)$ in the test sample and 38.51 years old $(S D=5.47)$ in the replication sample. For about half of the families, the twins were the firstborn children (test; $48.8 \%$, replication; 49.8\%), and most children were living in families with a high (test; 53.7\%, replication; 55.3\%) or middle (test; 36.8\%, replication; 36.4\%) socio-economic status (SES).

\section{Procedure}

For the current study, only data collected before the start of the intervention was included. From September 2015 to September 2016 all families were visited at home by two female research assistants. At the start of the home visit, the purpose and content of the study were explained. Both parents or legal representatives of the twin signed an informed consent. Next, a short interview was conducted. After the interview, the children were paired up with the research assistants. One of the children conducted some individual tasks in their own bedroom, while the other child performed some tasks with the primary parent in the living 
FAMILY STRESS AND CHILDREN'S BEHAVIORAL CONTROL

room. Half-way through the visit, the children switched places. The order of the tasks was counterbalanced. After the home visit, the primary parent received materials to perform ambulatory assessments, including the collection of noise recordings. The ambulatory assessments were conducted during four sequential days (two weekdays and two weekend days), and in most cases, within three weeks of the home visit. Furthermore, both parents were asked to fill out several computerized questionnaires about themselves and their children before the visit.

\section{Measurement instruments}

Cheating behavior. The children played a throwing game to assess their ability to internalize rules and maintain appropriate behavior, even when they are tempted to violate the rules (Kochanska, Murray, \& Coy, 1997). Before the game was played, children were told that they would receive a small prize after the game was played (colorful stamps) and that they would receive one extra prize for every ball that would stick on the velcro dart board. During the game, children had to stay behind a line and could throw each ball only once. After the instructions, children practiced the game with the research assistant. After the practice session, the research assistant moved the line further away from the board until the distance was approximately three meters, making it practically impossible for children to get a ball on the board without cheating. The camera of a tablet was used to videotape the child's actions without informing the child, and the research assistant instructed the child to play the game while she would check up on his or her sibling and mother or father. Three minutes later, the research assistant came back and handed the child one to four stamps and registered the number of balls on the board. Three undergraduate students were trained to code the videotapes on cheating behavior of the child together with the first author of this paper, using a coding scheme based on Zwirs et al. (2015). There were three categories of cheating behavior 1) no cheating, 2) possible intention to cheat, and 3) cheating. Cheating behavior 


\section{FAMILY STRESS AND CHILDREN'S BEHAVIORAL CONTROL}

was defined as throwing a ball after reducing the distance to the board, throwing more than three balls, or sticking one or more balls directly on the board. Possible intention to cheat was scored when a child broke one of the rules of the game, but did not enhance his or her chance of winning more prices by doing so. For example, when the child crossed the line to collect the balls but did not throw again, or when the child crossed the line, approached the dart board and was out of sight for a while without a clear indication of cheating. Coder reliability was computed based on 50 videotapes, 30 of these videotapes were coded directly after the training and the other 20 videotapes were coded when roughly half of the videotapes were coded. The average intraclass correlation coefficient (absolute agreement) for the three cheating categories based on 50 videotapes was .76 (range .65 - .87). Regular meetings were organized to prevent coder drift.

Effortful control. Two subscales of the Dutch short form of the Children's Behavior Questionnaire (CBQ) (Majdandzic \& van den Boom, 2007; Putnam \& Rothbart, 2006) were used to measure effortful control; attentional focusing (6 items) and inhibitory control (6 items). In the current study both parents were asked to independently rate how well the statements described the behavior of their children on a seven point scale (1= extremely untrue, 7 = extremely true). Parents could also indicate that they had never seen their child in the situation described, which led to a missing score. An example item is 'When drawing or coloring in a book, my child shows strong concentration'. Four items were reverse coded, such that a higher score indicated more effortful control. The reliability in both samples was good (test; $\alpha=.80$ for both parents, replication; $\alpha=.79$ for the primary parent and $\alpha=.82$ for the other parent). An average score of all items was computed for both the primary and other parent. The average score of both parents was combined into one average score since the correlation between the scores of both parents was high in both samples (test; $r=.56, p$ $<.001$, replication; $r=.54, p<.001$ ). If one of the parents did not fill out the CBQ (both 
FAMILY STRESS AND CHILDREN'S BEHAVIORAL CONTROL

samples; $n=15$ for the primary parent and $n=35$ for the other parent), the score of the parent who did fill out the questionnaire was taken as the final score. Ten children in both samples had missing CBQ data for both parents. No outliers were detected.

Household chaos. The primary parent reported on the level of household chaos using the Confusion, Hubbub and Order Scale (CHAOS) (Matheny, Wachs, Ludwig, \& Phillips, 1995). This questionnaire includes 15 statements like 'You can’t hear yourself think in our home' and 'We almost always seem to be rushed', answered on a five point scale $(1=$ extremely true, 5 = extremely untrue). The original English version of the questionnaire was back-translated to create a Dutch version. Seven items were reverse coded, such that a higher score indicated more household chaos. The reliability in both samples was good $(\alpha=.81)$. A sum score was used as the final score (Matheny et al., 1995). Two outlying values were detected in both samples and winsorized, such that the z-score would fall between -3.29 and 3.29, while retaining the original order in the data (Tabachnick \& Fidell, 2012). Fourteen families in both samples had missing values on household chaos.

Noise. Noise in the environment of the child was measured with the Language Environment Analysis system (LENA) (Greenwood, Thiemann-Bourque, Walker, Buzhardt, \& Gilkerson, 2011; Soderstrom \& Wittebolle, 2013, for more information see http://www.lenafoundation.org/Research/). The small, unobtrusive recorders were worn by the children in a special belt around their waist. Initially, families were asked to make recordings on two weekdays from 16:00 until the children went to bed and on a weekend day from 11:00 until the children went to bed. Since the total program of ambulatory assessments appeared to be too demanding for families, one weekday recording was dropped after four months of data collection. However, not all families strictly followed the instructions, leading to variations in the number of week- and weekend days and the length of the recordings. The LENA Pro software package was used to compute mean decibel levels and peak decibel 
FAMILY STRESS AND CHILDREN'S BEHAVIORAL CONTROL

levels for every five-minute interval. Only recordings that consisted of at least six complete five-minute intervals were included in the current study.

We computed a mean decibel level for week- and weekend days, by averaging the mean decibel level for all complete five-minute intervals during either week- or weekend days. Outlying values for week and weekend days were winsorized in both samples (Tabachnick \& Fidell, 2012). Furthermore, the standard deviation of the mean decibel level was computed as an indicator of variability in noise levels during week- and weekend days. Square root transformations were performed to approach a normal distribution of the variability data and outlying values were winsorized (Tabachnick \& Fidell, 2012).

In addition, LENA is able to segment the audio data and provide information on the percentage of time each particular segment (in total eight segments can be distinguished) is the predominant segment per five-minute interval. We included the average percentage of time 'silence' was the predominant segment on week- and weekend days in our analyses. Square root transformations were performed to approach a normal distribution of the data and outlying values were winsorized (Tabachnick \& Fidell, 2012).

The standard deviation of the mean decibel level and the average percentage silence related negatively to the mean decibel level and were therefore reverse coded such that higher scores on each of the noise variables indicated more noise in the environment of the child. The three variables were highly correlated on weekdays (test; $r$ 's $>.64, p<.001$, replication; $r$ 's $>.64, p<.001$ ) and weekend days (test; $r$ 's $>.84, p<.001$, replication; $r$ 's $>.81, p<$ .001).Therefore, all variables were standardized and then averaged, creating two final variables; noise on weekdays and noise on weekend days. This structure in the noise data was confirmed for both samples with a factor analysis. Noise on weekdays was missing for 57 children in the test sample and 66 children in the replication sample. Noise on weekend days was missing for 42 children in the test sample and 51 children in the replication sample. 
FAMILY STRESS AND CHILDREN'S BEHAVIORAL CONTROL

Crowding. During the home visit, a short interview was conducted to establish the number of persons living in the house, and the number of rooms in the house in which family members spend time and that can be closed by a door (excluding for example storage spaces and open kitchens). Separate toilets were not included, but bathrooms were. A people to rooms ratio was calculated by dividing the number of persons living in the house by the number of rooms. In addition, we calculated a people to square meters ratio. In the Netherlands, municipalities provide online information about the surface area of a house (usable space only). We divided the number of people living in the house by the surface area. Since the correlation between the two indicators of crowding was high (test; $r=.56, p<.001$, replication; $r=.51, p<.001$ ), we computed an average ratio based on the standardized ratios. Higher scores on this variable indicated more crowding. We winsorized three outliers in both samples (Tabachnick \& Fidell, 2012), there were no missing data.

Parenting Daily Hassles. The level of parenting daily hassles was assessed with the Dutch version of the Parenting Daily Hassles questionnaire (PDH) (Crnic \& Greenberg, 1990; Rutgers et al., 2007). This questionnaire includes 20 items describing situations that may be stressful when rearing young children, like 'continually cleaning up messes of toys or food' and 'the kids resist or struggle with you over bed-time'. Both the frequency, i.e., how often the situation occurred in the last week, and intensity, i.e., how much of a hassle it was for the parent, were rated by the primary parent on a five point scale $(0=$ never/not a hassle, $4=$ constantly/big hassle). Because the frequency and intensity subscales were highly correlated (test; $r=.78, p<.001$, replication; $r=.79, p<.001$ ), the standardized average frequency and intensity rating were combined into one overall parenting daily hassles score. The reliability of the combined items was high in both samples $(\alpha=.91)$. Two outliers in both samples were winsorized (Tabachnick \& Fidell, 2012), twelve children in both samples had missing values. 
FAMILY STRESS AND CHILDREN'S BEHAVIORAL CONTROL

Parental depressive symptoms. Both parents reported on the level of depressive symptoms they experienced in the past week on a five-point scale $(0=$ not at all, $4=$ a lot $)$ using the Dutch version of the depression subscale (6 items) of the Brief Symptom Inventory (BSI; de Beurs \& Zitman, 2006; Derogatis \& Melisaratos, 1983). An average score was computed for both parents separately, higher scores indicated more depressive symptoms. Square root transformations were performed to approach a normal distribution of the data, and outlying values ( 4 primary parents and 1 other parent in both samples) were winsorized (Tabachnick \& Fidell, 2012). The reliability of the subscale was good (test; $\alpha=.84$ for both parents, replication; $\alpha=.84$ for the primary parent and $\alpha=.82$ for the other parent). There were missing values for 14 primary parents and 37 other parents in both samples.

Response bias. Response bias was examined using six non-credible items from the Dutch Wildman Symptoms Checklist (WSC) (Merckelbach, Smeets, \& Jelicic, 2008) and four items that we created ourselves for the current study, see the appendix for more information. No deviant response patterns were detected.

Zygosity. We used a zygosity questionnaire and the accompanying algorithm (Rietveld et al., 2000) to categorize the twins as either monozygotic or dizygotic. The questionnaire includes items informing on how much the children look alike with respect to hair color and height for example, and on the frequency their parents and other people mistake one for the other. The questionnaire was filled out by the primary parent, in the second year of the L-CID preschooler project. For seven families with missing data, the zygosity score in the second year was estimated based on the score in the first year. Rietveld et al. (2000) compared the results of the questionnaire to the results of DNA analysis/blood typing and found that the zygosity classification was correct in about $93 \%$ of the cases.

\section{Analysis plan}


FAMILY STRESS AND CHILDREN'S BEHAVIORAL CONTROL

We performed behavior-genetics analyses using Open Mx in R to investigate whether variance in effortful control and cheating behavior was best explained by heritability, shared or unique environmental factors, fitting the ACE model to the data. Furthermore, we computed mean's and standard deviation's for the outcome variables, all predictors (noise week, noise weekend, crowding, depression of both parents, parenting daily hassles and parent reported household chaos), and covariates (SES, child age and gender) and explored the relations between these variables using SPSS 23.

To ensure that the path models would not be more complicated than necessary, we first inspected the covariances among the predictor variables and the covariates. In this preliminary phase, all predictor variables were regressed on the covariates and the covariances between predictor variables were estimated. To ensure that fit-indices in both samples would not be influenced by misspecification of covariances, parameters that were at least borderline significant $(p<.10)$ in the test sample or in the replication sample were retained in the main models.

We then tested the main models with effortful control and cheating (nominal variable) as outcome variables in the test sample. Of the three categories 'no cheating', 'intention to cheat', and 'cheating' the latter was used as the reference category. In order to avoid large differences between variances of predictors in the path-models, chaos values were divided by ten. In the first step, we tested a full model that freely estimated all paths between the predictors, the covariates, and the outcome variable. In the next step we tested a more parsimonious model, in which the covariates were retained, but non-significant paths between the predictors and outcome variable were excluded. Then, we evaluated the plausibility of the parsimonious model in the replication sample.

All models were estimated with Maximum Likelihood estimation with robust standard errors (MLR) because the depression variables were still skewed after transformation. To 
FAMILY STRESS AND CHILDREN'S BEHAVIORAL CONTROL

assess model fit, we inspected the $\chi^{2}$ and the ratio between $\chi^{2}$ and degrees of freedom. A ratio smaller than 2.0 indicates a good model fit (Hu \& Bentler, 1999; Ullman, 2001). Also the CFI, TLI, and RMSEA were examined. CFI and TLI values above .95 and RMSEA values lower than .05 indicate that the data fit the model well (Ullman, 2001). Because of the categorical nature of cheating behavior, only few fit indices were available for this outcome variable (Muthén \& Muthén, 1998-2015). To compare nested models, we used the $\chi^{2}$ difference test for the difference in Log Likelihood with a scaling correction factor that is used for MLR estimation.

Missing data of both models were handled with the default methods in Mplus: Maximum Likelikhood imputation, and in the case of the nominal outcome variable cheating, Monte Carlo integration was used with 150 integration points (Muthén \& Muthén, 19982015).

\section{Results}

\section{Preliminary analyses}

Descriptive statistics and correlations between the predictor variables, the covariates and outcome variables in the test and replication sample are shown in Table 1. In both samples a higher level of depressive symptoms of both parents was related to more parenting daily hassles and self-reported household chaos. With regard to the covariates, lower SES was related to higher levels of depressive symptoms reported by the primary parent, parenting daily hassles, self-reported household chaos and crowding in both samples. Furthermore, we found that noise levels on weekend days were higher for older children in both samples. As far as the two main outcome variables are concerned, in the test sample, children in the cheating group had significantly lower scores on effortful control than children in the possible intention to cheat group. In the replication sample, there were no significant relations between these constructs. 
FAMILY STRESS AND CHILDREN'S BEHAVIORAL CONTROL

INSERT TABLE 1 AROUND HERE

\section{Path model for effortful control}

First, we tested the full model with children's effortful control as outcome variable in the test sample. More depressive symptoms of the other parent and more parenting daily hassles significantly predicted lower levels of effortful control in children. In the next step we tested a more parsimonious model, excluding non-significant paths between predictor variables and children's effortful control, but retaining the covariates (see Figure 1a). The fitindices of this more parsimonious model indicated a good model fit (see Table 2).

Furthermore, the difference between the Log Likelihood of the full model and the parsimonious model was not significant, and therefore the more parsimonious model was preferred. More parenting daily hassles $(\beta=-.26$, 95\% CI of $\beta$, lower $=-.335$, upper $=-.097$, $p<.01$; see Figure 1a) and more depressive symptoms of the other parent $(\beta=-.18,95 \%$ CI of $\beta$, lower $=-.330$, upper $=-.029, p=.02$; see Figure $1 \mathrm{a}$ ) were significantly related to lower levels of effortful control in the test sample.

We then tested the plausibility of this parsimonious model in the replication sample. Results showed that the parsimonious model fitted the data in the replication sample well (see Table 2). When compared to a full model, we found no significant difference in Log Likelihood which suggests that the parsimonious model should be preferred. The significant negative effect of parenting daily hassles on children's effortful control was replicated in the replication sample $(\beta=-.22, p<.01$; see Figure $1 \mathrm{a})$; again, children of parents reporting more daily hassles had lower effortful control scores. Depression of the other parent was not a significant predictor of effortful control in the replication sample $(\beta=-.11, p=.13$; see Figure 1a). To examine the difference between the regression weights of depression of the other parent in the two samples, we checked if the regression weight in the replication sample fell within the range of the $95 \%$ confidence interval of the regression weight in the test sample. 
FAMILY STRESS AND CHILDREN'S BEHAVIORAL CONTROL

This was indeed the case, which suggested that the effect of depression of the other parent was not incompatible with the model of the test sample.

INSERT FIGURE 1 AND TABLE 2 AROUND HERE

\section{Path model for cheating behavior}

Results of the full model with cheating behavior as outcome variable showed that both self-reported household chaos and crowding were significantly related to cheating behavior in the test sample, with higher levels household chaos and of crowding increasing the risk of being in the cheating group versus the intention to cheat group. Next, we tested a more parsimonious model excluding non-significant paths between the predictor variables and cheating, but retaining the covariates in the model (see Figure 1b). The non-significant difference in Log Likelihood suggested that the more parsimonious model should be preferred (see Table 3). Children growing up in more chaotic (OR = .54, 95\% CI of OR, lower = .307, upper $=.951, p=.03$; see Figure $1 \mathrm{~b})$ and more crowded houses $(\mathrm{OR}=0.64,95 \% \mathrm{CI}$ of OR, lower $=.477$, upper $=.861, p<.01$; see Figure $1 \mathrm{~b}$ ) were less likely to end up in the possible intention to cheat group than the cheating group.

We then tested the same parsimonious model in the replication sample. The nonsignificant difference in Log Likelihood between the full and parsimonious model suggested that the parsimonious model should be preferred (see Table 3). Household chaos was not a significant predictor of effortful control in the replication sample. However, the odds ratio value of the relation between household chaos and cheating versus possible intention to cheat in the replication sample (OR $=.86, p=.53$ ) fell within the range of the $95 \%$ confidence interval of the test sample, suggesting that the effect of household chaos was not incompatible with the model of the test sample. Crowding was also no longer a significant predictor of cheating behavior (see Figure 1b). Furthermore, the odds ratio value of the relation between 
FAMILY STRESS AND CHILDREN'S BEHAVIORAL CONTROL

crowding and cheating versus possible intention to cheat in the replication sample $(\mathrm{OR}=1.14$, $p=.22$ ) did not fall within the range of the $95 \%$ confidence interval of the test sample.

\section{INSERT TABLE 3 AROUND HERE}

\section{Behavior-genetics analyses}

Behavior-genetics analyses were performed for children's effortful control and 'no cheating vs. cheating'. For these specific analyses, only families who completed the zygosity questionnaire and in which both children had cheating data were included ( $n=186,53.2 \%$ monozygotic, $48.4 \%$ boys). Of these families, 6 did not complete the CBQ, therefore the sample size for the analysis with effortful control was 180 (53\% monozygotic). For both variables, AE models fitted the data best. We found that $31 \%$ of the variance in effortful control was heritable and $16 \%$ of the variance in 'no cheating vs. cheating'. The rest of the variance was explained by the unique environment of the child and/or measurement error. Shared environmental factors did not significantly contribute to the variance in children's behavioral control.

\section{Discussion}

Children's effortful control was found to be negatively associated with parenting daily hassles and depressive symptoms of the other parent; children of parents experiencing high levels of parenting daily hassles and depressive symptoms had lower levels of effortful control than children in families with low levels of family stress. For children’s cheating behavior we only found a consistent relation with parent reported household chaos; children growing up in more chaotic households had an increased risk of being in the cheating group versus the possible intention to cheat group. The relation between crowding and children's cheating behavior was not consistent; children growing up in more crowded houses were less likely to end up in the possible intention to cheat group than in the cheating group, but this effect was only found in one of the samples. In addition, we explored the effects of 
FAMILY STRESS AND CHILDREN'S BEHAVIORAL CONTROL

environmental and genetic factors on children's behavioral control, using behavior-genetics analyses. Surprisingly, AE models fitted the data for effortful control and cheating versus no cheating best. The majority of the variance in effortful control and cheating behavior was explained by the unique environment of the children and/or measurement error (69\% and 84\% respectively). Genetic factors also played a significant role, about one-third (31\%) of the variance in effortful control and $16 \%$ of the variance in cheating behavior was heritable.

The strengths of the current study are the test and replication design and the multimethod, multi-informant approach. We created two samples, a test and a replication sample, by randomly dividing children of the same twin pair. This design enabled us to test the associations between the environmental factors and children's behavioral control in one group, and to examine the replicability of these effects in a second group. Replication is essential for science (Simons, 2014). A recent multilab replication study showed that the results of an experiment by Strack, Martin, and Stepper (1988) could not be replicated (Wagenmakers, Beek, Dijkhoff, \& Gronau, 2016), thereby stressing the importance of this type of research. However, a study focusing on psychology publications since 1900, found an overall replication rate of only 1.07\% (Makel, Plucker, \& Hegarty, 2012). Another strength of the study is the fact that behavioral control of the children was measured in two ways: both parents reported independently on the level of their children's effortful control and the child's actual cheating behavior was observed during a throwing game. For household chaos, we also included more objective indicators, namely noise and crowding, next to a well-validated selfreport questionnaire (Matheny et al., 1995).

Our finding that children of parents experiencing high levels of parenting daily hassles and depressive symptoms had lower levels of effortful control than children of parents that did not experience these kinds of stress is in line with previous studies (Barry et al., 2005; Coplan et al., 2003; Gartstein \& Fagot, 2003; Mathis \& Bierman, 2015; Sektnan et al., 2010). 


\section{FAMILY STRESS AND CHILDREN'S BEHAVIORAL CONTROL}

There might be several interpretations for this association. Growing up in a stressful environment might, on the one hand, directly undermine the development of children's behavioral control. On the other hand, the association might be mediated by other environmental family factors, such as parenting practices. Indeed, both parenting daily hassles and parental depressive symptoms have been associated with less positive parenting (Crnic et al., 2005; Cummings et al., 2005), and less positive parenting was found to predict lower levels of effortful control (Eisenberg et al., 2005). Furthermore, it is possible that stressed or depressive parents perceive or interpret their child's behavior more negatively and therefore report lower levels of effortful control. However, in the current study, we combined the reports of the primary and other parent regarding their children's effortful control. Thereby, reducing the chance that we measured biased perception, rather than actual child behavior.

Although we found a significant correlation in both samples indicating that more household chaos as reported by the primary parent was related to lower levels of children's effortful control, none of the indicators of household chaos significantly predicted children's effortful control when we controlled for the other variables in the model. The lack of such an association might be caused by the relatively strong association between parenting daily hassles and household chaos. Some of the daily hassles parents experienced might be associated with or caused by the unstructured, uncontrollable environment they created for their family. Effects of household chaos on children's behavioral control might therefore be at least partly confounded with parenting daily hassles, which would explain the absence of a direct effect of household chaos in the path model. The lack of an association between depressive symptoms of the primary parent and children's effortful control may also be explained by the association between the depressive symptoms of this parent and the level of parenting daily hassles. The effect of parenting daily hassles, as reported by the primary parent, may potentially overshadow the effect of depression of this parent. 
FAMILY STRESS AND CHILDREN'S BEHAVIORAL CONTROL

The relation between household chaos as reported by the primary parent and children's cheating behavior is also in line with previous research (Evans et al., 2005; Hardaway et al., 2012; Valiente et al., 2007; Hur et al., 2015; Martin et al., 2012). All other indicators of a stressful family environment were, different from what we expected, not consistently related to children's cheating behavior. This lack of further associations might originate from the assessment method. It could be argued that cheating behavior during the throwing game is actually an indicator of children’s moral development instead of children's behavioral regulation. Kochanska et al. (1997) used the throwing game as an indicator of children's internalized conscience. According to Kochanska and Aksan (2006) important predictors of moral conduct in children are their level of effortful control and fearfulness, parental discipline strategies and the quality of the parent-child relationship.

In contrast to what we expected, no significant shared environmental influences were found in the behavior-genetics analyses, although the path analyses did reveal some significant relations between indicators of a stressful family environment and children’s behavioral control. One explanation for the absence of a C component could be that ACE analyses in samples of modest size leave room for undetected but important parts of the variance explained by the shared environment. Another explanation might be that genetic effects are mediated by shared environmental factors. The genetic make-up of parents is passed on to their children, but also influences the environments parents shape for their children. Genes affecting behavioral control may also relate to the ability of parents to create a stable and structured environment, which is in turn related to their stress level and depressive symptoms. And the children's inherited genetic make-up in its turn might select specific environmental features that have important impact on their behavior and development, thus creating gene-environment correlation (Knafo \& Jaffee, 2013). Further research should look into these possibilities. Furthermore, it is important in future studies to 
FAMILY STRESS AND CHILDREN'S BEHAVIORAL CONTROL

assess each co-twin's unique perception of parenting styles and more or less subtle differences in parental treatment of each co-twin to uncover what is hidden behind the large percentages of $\mathrm{E}$, that is unique environment or error.

It is important to consider a few limitations of the current study when interpreting the results. First of all, it is important to note that zygosity classifications were based on questionnaire data rather than the comparison of DNA markers. Therefore, we cannot be $100 \%$ sure that all classifications were correct. A previous study however, showed that in 93\% of the cases, the classification based on the questionnaire we used was correct (Rietveld et al., 2000). Furthermore, it is important to recognize that the replication sample was not independent of the test sample, since children of the same twin pair were randomly divided over a test and replication sample. The advantage, however, is the optimal match for birth dates, family background, and in many (MZ) cases even structural DNA make-up. Matching a replication sample to a test sample this way means that very few alternative interpretations remain when test results cannot be replicated. Lastly, the range of most variables was restricted because of the non-clinical and primarily lower-middle to higher SES background of the sample, and transformations may not always have solved skewness completely.

\section{Conclusion}

The findings of the current study indicate that children of parents experiencing more daily hassles or depressive symptoms show lower levels of behavioral control as reported by their parents. Furthermore, we found that children growing up in more chaotic households had an increased risk of being in the cheating group versus the possible intention to cheat group. Since young children's behavioral control predicts a broad range of developmental outcomes in childhood and adulthood, it is important to search for correlates of the ability of young children to control their behavior. The current study suggests that we need to consider the role of a stressful family environment in the development of behavioral control when preventive 
FAMILY STRESS AND CHILDREN'S BEHAVIORAL CONTROL

intervention programs such as the VIPP-SD (Juffer, Bakermans-Kranenburg, \& Van IJzendoorn, 2017) and Incredible Years (Gardner \& Leijten, 2017) aiming at increasing children’s behavioral control are implemented and tested.

\section{Acknowledgements}

The authors thank the families for their participation in the L-CID preschooler project and the people involved in the data collection, especially Rani C. Damsteegt and Ilse de Visser. Three of the authors are members of the Leiden Consortium on Individual Development (L-CID) which is funded through the Gravitation program of the Dutch Ministry of Education, Culture, and Science and the Netherlands Organization for Scientific Research (NWO grant number 024.001.003). Additional funding was provided by the Netherlands Organization for Scientific Research to the third author (NWO SPINOZA prize).

\section{Author notes}

Some of the data appearing in this manuscript was presented on a meeting of the Consortium on Individual Development and the research days of the Institute of the Study of Education and human Development.

\section{References}

Barry, T. D., Dunlap, S. T., Cotten, S. J., Lochman, J. E., \& Wells, K. C. (2005). The influence of maternal stress and distress on disruptive behavior problems in boys. Journal of the American Academy of Child and Adolescent Psychiatry, 44(3), 265273. doi: 10.1097/00004583-200503000-00011

Bronson, M. B. (2000). Self-regulation in earl childhood: Nature and nurture. New York: The Guilford Press.

Coplan, R. J., Bowker, A., \& Cooper, S. M. (2003). Parenting daily hassles, child temperament, and social adjustment in preschool. Early Childhood Research Quarterly, 18(3), 376-395. doi: 10.1016/S0885-2006(03)00045-0 
FAMILY STRESS AND CHILDREN'S BEHAVIORAL CONTROL

Crnic, K. A., Gaze, C., \& Hoffman, C. (2005). Cumulative parenting stress across the preschool period: Relations to maternal parenting and child behaviour at age 5. Infant and Child Development, 14(2), 117-132. doi: 10.1002/icd.384

Crnic, K. A., \& Greenberg, M. T. (1990). Minor parenting stresses with young children. Child Development, 61(5), 1628-1637.

Cummings, E. M., Keller, P. S., \& Davies, P. T. (2005). Towards a family process model of maternal and paternal depressive symptoms: exploring multiple relations with child and family functioning. Journal of Child Psychology and Psychiatry, 46(5), 479-489. doi: 10.1111/j.1469-7610.2004.00368.x

de Beurs, E., \& Zitman, F. G. (2006). De Brief Symptom Inventory (BSI): De betrouwbaarheid en validiteit van een handzaam alternatief voor de SCL-90. Maandblad Geestelijke Volksgezondheid, 61, 120-141.

Derogatis, L. R., \& Melisaratos, N. (1983). The Brief Symptom Inventory - an Introductory Report. Psychological Medicine, 13(3), 595-605.

Dumas, J. E., Nissley, J., Nordstrom, A., Smith, E. P., Prinz, R. J., \& Levine, D. W. (2005). Home chaos: Sociodemographic, parenting, interactional, and child correlates. Journal of Clinical Child and Adolescent Psychology, 34(1), 93-104. doi: 10.1207/s15374424jccp3401_9

Eisenberg, N., Zhou, Q., Spinrad, T. L., Valiente, C., Fabes, R. A., \& Liew, J. (2005). Relations among positive parenting, children's effortful control, and externalizing problems: A three-wave longitudinal study. Child Development, 76(5), 1055-1071. doi: 10.1111/j.1467-8624.2005.00897.x

Euser, S., Bakermans-Kranenburg, M. J., Van den Bulk, B. G., Linting, M., Damsteegt, R. C., Vrijhof, C. I., . . V Van IJzendoorn, M. H. (2016). Efficacy of the Video-feedback Intervention to promote Positive parenting and Sensitive Discipline in Twin Families 
FAMILY STRESS AND CHILDREN'S BEHAVIORAL CONTROL

(VIPP-Twins): Study protocol for a randomized controlled trial. BMC Psychology, 4(3). doi: 10.1186/s40359-016-0139-y

Evans, G. W., Gonnella, C., Marcynyszyn, L. A., Gentile, L., \& Salpekar, N. (2005). The role of chaos in poverty and children's socioemotional adjustment. Psychological Science, 16(7), 560-565. doi: 10.1111/j.0956-7976.2005.01575.x

Gagne, J. R., \& Saudino, K. J. (2016). The Development of Inhibitory Control in Early Childhood: A Twin Study From 2-3 Years. Developmental Psychology, 52(3), 391399. doi: $10.1037 / \operatorname{dev} 0000090$

Gardner, F., \& Leijten, P. (2017). Incredible Years Parenting Interventions: Current Effectiveness Research and Future Directions. Current Opinion in Psychology, 15, 99104.

Gartstein, M. A., \& Fagot, B. I. (2003). Parental depression, parenting and family adjustment, and child effortful control: Explaining externalizing behaviors for preschool children. Journal of Applied Developmental Psychology, 24(2), 143-177. doi: 10.1016/S01933973(03)00043-1

Goodman, S. H., \& Gotlib, I. H. (1999). Risk for psychopathology in the children of depressed mothers: A developmental model for understanding mechanisms of transmission. Psychological Review, 106(3), 458-490. doi: 10.1037/0033295x.106.3.458

Greenwood, C. R., Thiemann-Bourque, K., Walker, D., Buzhardt, J., \& Gilkerson, J. (2011). Assessing Children's Home Language Environments Using Automatic Speech Recognition Technology. Communication Disorders Quarterly, 32(2), 83-92. doi: $10.1177 / 1525740110367826$ 
FAMILY STRESS AND CHILDREN'S BEHAVIORAL CONTROL

Hanscombe, K. B., Haworth, C. M. A., Davis, O. S. P., Jaffee, S. R., \& Plomin, R. (2011). Chaotic homes and school achievement: a twin study. Journal of Child Psychology and Psychiatry, 52(11), 1212-1220. doi: 10.1111/j.1469-7610.2011.02421.x

Hardaway, C. R., Wilson, M. N., Shaw, D. S., \& Dishion, T. J. (2012). Family Functioning and Externalizing Behaviour among Low-income Children: Self-regulation as a Mediator. Infant and Child Development, 21(1), 67-84. doi: 10.1002/icd.765

Hu, L. T., \& Bentler, P. M. (1999). Cutoff Criteria for Fit Indexes in Covariance Structure Analysis: Conventional Criteria Versus New Alternatives. Structural Equation Modeling-a Multidisciplinary Journal, 6(1), 1-55. doi: 10.1080/10705519909540118

Hur, E., Buettner, C. K., \& Jeon, L. (2015). Parental Depressive Symptoms and Children's School-Readiness: The Indirect Effect of Household Chaos. Journal of Child and Family Studies, 24(11), 3462-3473. doi: 10.1007/s10826-015-0147-1

Juffer, F., Bakermans-Kranenburg, M.J., \& Van IJzendoorn, M.H. (2017). Pairing attachment theory and social learning theory in video-feedback intervention to promote positive parenting. Current opinion in psychology, 15, 189-194.

Knafo, A., \& Jaffee, S. R. (2013). Gene-environment correlation in developmental psychopathology. Dev Psychopathol, 25(1), 1-6. doi:10.1017/S0954579412000855

Kochanska, G., \& Aksan, N. (2006). Children's conscience and self-regulation. Journal of Personality, 74(6), 1587-1617. doi: 10.1111/j.1467-6494.2006.00421.x

Kochanska, G., Murray, K., \& Coy, K. C. (1997). Inhibitory control as a contributor to conscience in childhood: From toddler to early school age. Child Development, 68(2), 263-277. doi: 10.1111/j.1467-8624.1997.tb01939.x

Kopp, C. B. (1982). Antecedents of self-regulation: A developmental perspective. Developmental Psychology, 18(2), 199-214. doi: 10.1037//0012-1649.18.2.199 
FAMILY STRESS AND CHILDREN'S BEHAVIORAL CONTROL

Majdandzic, M., \& van den Boom, D. C. (2007). Multimethod longitudinal assessment of temperament in early childhood. Journal of Personality, 75(1), 121-168. doi: 10.1111/j.1467-6494.2006.00435.x

Makel, M. C., Plucker, J. A., \& Hegarty, B. (2012). Replications in Psychology Research: How Often Do They Really Occur? Perspectives on Psychological Science, 7(6), 537542. doi: $10.1177 / 1745691612460688$

Martin, A., Razza, R., \& Brooks-Gunn, J. (2012). Specifying the Links Between Household Chaos and Preschool Children's Development. Early Child Development and Care, 182(10), 1247-1263. doi: 10.1080/03004430.2011.605522

Matheny, A. P., Wachs, T. D., Ludwig, J. L., \& Phillips, K. (1995). Bringing Order out of Chaos - Psychometric Characteristics of the Confusion, Hubbub, and Order Scale. Journal of Applied Developmental Psychology, 16(3), 429-444. doi: 10.1016/01933973(95)90028-4

Mathis, E. T. B., \& Bierman, K. L. (2015). Dimensions of Parenting Associated with Child Prekindergarten Emotion Regulation and Attention Control in Low-income Families. Social Development, 24(3), 601-620. doi: 10.1111/sode.12112

McClelland, M. M., Cameron, C. E., Connor, C. M., Farris, C. L., Jewkes, A. M., \& Morrison, F. J. (2007). Links between behavioral regulation and preschoolers' literacy, vocabulary, and math skills. Developmental Psychology, 43(4), 947-959. doi: 10.1037/0012-1649.43.4.947

Merckelbach, H., Smeets, T., \& Jelicic, M. (2008). Onwaarschijnlijke symptomen simuleren: de Wildman Symptom Checklist. NeuroPraxis, 2, 53-57.

Moffitt, T. E., Arseneault, L., Belsky, D., Dickson, N., Hancox, R. J., Harrington, H., . . . Caspi, A. (2011). A gradient of childhood self-control predicts health, wealth, and public safety. PNAS, 108(7), 2693-2698. doi: 10.1073/pnas.1010076108 
FAMILY STRESS AND CHILDREN'S BEHAVIORAL CONTROL

Muris, P., van der Pennen, E., Sigmond, R., \& Mayer, B. (2008). Symptoms of anxiety, depression, and aggression in non-clinical children: relationships with self-report and performance-based measures of attention and effortful control. Child Psychiatry and Human Development, 39(4), 455-467. doi: 10.1007/s10578-008-0101-1

Muthén, L. K., \& Muthén, B. O. (1998-2015). Mplus User’s Guide (7th ed.). Los Angeles, CA: Muthén \& Muthén.

Putnam, S. P., \& Rothbart, M. K. (2006). Development of short and very short forms of the Children's Behavior Questionnaire. Journal of Personality Assessment, 87(1), 102112. doi: 10.1207/s15327752jpa8701_09

Ramchandani, P., Stein, A., Evans, J., O'Connor, T. G., \& Team, A. S. (2005). Paternal depression in the postnatal period and child development: a prospective population study. Lancet, 365(9478), 2201-2205. doi: 10.1016/S0140-6736(05)66778-5

Rietveld, M. J., van Der Valk, J. C., Bongers, I. L., Stroet, T. M., Slagboom, P. E., \& Boomsma, D. I. (2000). Zygosity diagnosis in young twins by parental report. Twin Research, 3(3), 134-141.

Rijlaarsdam, J., Stevens, G. W. J. M., van der Ende, J., Hofman, A., Jaddoe, V. W. V., Mackenbach, J. P., ... Tiemeier, H. (2013). Economic Disadvantage and Young Children's Emotional and Behavioral Problems: Mechanisms of Risk. Journal of Abnormal Child Psychology, 41(1), 125-137. doi: 10.1007/s10802-012-9655-2

Rothbart, M. K., \& Bates, J. E. (2006). Temperament. In N. Eisenberg, W. Damon, \& R. M. Lerner (Eds.), Handbook of child psychology: Social, Emotional, and Personality Development (6th ed., Vol. 3). Hoboken, NJ: John Wiley \& Sons Inc.

Rutgers, A. H., van IJzendoorn, M. H., Bakermans-Kranenburg, M. J., Swinkels, S. H., van Daalen, E., Dietz, C., . . van Engeland, H. (2007). Autism, attachment and parenting: a comparison of children with autism spectrum disorder, mental retardation, language 
FAMILY STRESS AND CHILDREN'S BEHAVIORAL CONTROL

disorder, and non-clinical children. Journal of Abnormal Child Psychology, 35(5), 859-870. doi: 10.1007/s10802-007-9139-y

Sektnan, M., McClelland, M. M., Acock, A., \& Morrison, F. J. (2010). Relations between early family risk, children's behavioral regulation, and academic achievement. Early Childhood Research Quarterly, 25(4), 464-479. doi: 10.1016/j.ecresq.2010.02.005

Shamama-tus-Sabah, S., Gilani, N., Kamal, A., \& Batool, S. (2012). Chaotic Home Conditions and Children's Adjustment: Study of Gender Differences. Pakistan Journal of Psychological Research, 27, 297-313.

Shelleby, E. C., Votruba-Drzal, E., Shaw, D. S., Dishion, T. J., Wilson, M. N., \& Gardner, F. (2014). Income and Children's Behavioral Functioning: A Sequential Mediation Analysis. Journal of Family Psychology, 28(6), 936-946. doi: 10.1037/fam0000035

Simons, D. J. (2014). The Value of Direct Replication. Perspectives on Psychological Science, 9(1), 76-80. doi: 10.1177/1745691613514755

Soderstrom, M., \& Wittebolle, K. (2013). When Do Caregivers Talk? The Influences of Activity and Time of Day on Caregiver Speech and Child Vocalizations in Two Childcare Environments. Plos One, 8(11). doi: ARTN e8064610.1371/journal.pone. 0080646

Spinrad, T. L., Eisenberg, N., Gaertner, B., Popp, T., Smith, C. L., Kupfer, A., .. . Hofer, C. (2007). Relations of maternal socialization and toddlers' effortful control to children's adjustment and social competence. Developmental Psychology, 43(5), 1170-1186. doi: 10.1037/0012-1649.43.5.1170

Strack, F., Martin, L. L., \& Stepper, S. (1988). Inhibiting and facilitating conditions of the human smile: a nonobtrusive test of the facial feedback hypothesis. Journal of Personality and Social Psychology, 54(5), 768-777. 
FAMILY STRESS AND CHILDREN'S BEHAVIORAL CONTROL

Tabachnick, B. G., \& Fidell, L. S. (2012). Using multivariate statistics (6th ed.). New York, NY: Harper Collins.

Ullman, J. B. (2001). Structural equation modeling. In B. G. Tabachnick \& L. S. Fidell (Eds.), Using Multivariate Statistics (4th ed., pp. 653- 771). Needham Heights, MA: Allyn \& Bacon.

Valiente, C., Lemery-Chalfant, K., \& Reiser, M. (2007). Pathways to problem behaviors: Chaotic homes, parent and child effortful control, and parenting. Social Development, 16(2), 249-267. doi: 10.1111/j.1467-9507.2007.00383.x

Wachs, T. D. (1989). The Nature of the Physical Microenvironment - an Expanded Classification-System. Merrill-Palmer Quarterly-Journal of Developmental Psychology, 35(4), 399-419.

Wachs, T. D., \& Evans, G. W. (2010). Chaos and its influence on children’s development: An ecological perspective. In G. W. Evans \& T. D. Wachs (Eds.), Chaos in context (pp. 3-13). Washington, DC: American Psychological Association.

Wagenmakers, E. J., Beek, T., Dijkhoff, L., \& Gronau, Q. F. (2016). Registered Replication Report: Strack, Martin, \& Stepper (1988). Perspectives on Psychological Science. doi: $10.1177 / 1745691616674458$

Yamagata, S., Takahashi, Y., Kijima, N., Maekawa, H., Ono, Y., \& Ando, J. (2005). Genetic and environmental etiology of effortful control. Twin Research and Human Genetics, 8(4), 300-306. doi: 10.1375/1832427054936790

Zwirs, B. W. C., Szekely, E., Herba, C. M., Verhulst, F. C., Jaddoe, V. W. V., Hofman, A., . . . Tiemeier, H. (2015). Social and non-social fear in preschoolers and prospective associations with lying about cheating. International Journal of Behavioral Development, 39(5), 477-484. doi: 10.1177/0165025414553136 